\title{
Metals Determination in Biodiesel (B100) by ICP-OES with Microwave Assisted Acid Digestion
}

\author{
Javed Iqbal ${ }^{1}$, William A. Carney ${ }^{1}$, Shelly LaCaze ${ }^{1}$ and Chandra S. Theegala ${ }^{*}, 2$ \\ ${ }^{I}$ WA Callegari Environmental Center, LSU AgCenter, Baton Rouge, LA, USA \\ ${ }^{2}$ Department of Biological \& Agriculture Engineering, LSU AgCenter, Baton Rouge, LA, USA
}

\begin{abstract}
Elemental composition of biodiesel is required for product quality-control, auto-engine life, emissions control, and researching appropriate additives. The use of microwave assisted acid digestion reaction system to prepare neat biodiesel (B100) samples in an aqueous medium for simultaneous inductively coupled plasma optical emission spectrometer (ICP-OES) analyses is reported. Biodiesel produced by transesterification reaction was subjected to the test method using calibration standards prepared in an aqueous medium. Significant correlation for the spiked B100 samples, instrument detection limits, accuracy, and precision data showed that elemental concentrations can easily be determined within the specified limits. The method avoids switching any of the ICP-OES accessories required for high organic loads. This method is most appropriately devised for biodiesel analysis than petrochemicals analysis.
\end{abstract}

Keywords: Biodiesel, transesterification, metals analysis, B100, microwave digestion, ICP-OES, fatty acid methyl esters, ASTM, auto-emissions.

\section{INTRODUCTION}

The rising cost and environmental impacts associated with petroleum-based fuels has led to the exploration of a renewable alternative fuel - Biodiesel. Biodiesel, defined as a mixture of mono-alkyl esters, is produced from a wide range of vegetable oils and animal fats more commonly by a lipid transesterification process [1-3]. Biodiesel can be substituted for petroleum-based diesel fuel (petrodiesel) in virtually any standard unmodified diesel engine $[4,5]$. Pure biodiesel or biodiesel blended with petroleum diesel can be used to fuel diesel vehicles, providing energy security and emissions and safety benefits.

A consistent quality assurance program is necessary to avoid performance issues in vehicle engines and to ensure sustainable growth of biodiesel production. Inorganic constituents in the final product can promote residue build up in the engine, cause corrosion and ultimately affect engine life. Elements introduced during production process $(\mathrm{Na}, \mathrm{K}, \mathrm{Ca}$, and $\mathrm{Mg}$ ) are of particular concern, while other elements present in the feedstock $(\mathrm{P}, \mathrm{S}$, and $\mathrm{Zn})$, or used as additives ( $\mathrm{Si}, \mathrm{Mn}, \mathrm{Cr}, \mathrm{Fe}$, and $\mathrm{Ni}$ ) require monitoring in order to avoid undesirable combustion products in the engines [6]. Since metallic elements in fuel are undesirable even at lower concentrations, their determination in fuel is necessary to evaluate fuel quality, to see their effect on auto engines, and to control environmental pollution.

\subsection{Significance of Metals Analyses}

Since the concentration of metals in biodiesel is generally low, the use of highly sensitive analytical techniques is

\footnotetext{
*Address correspondence to this author at the Department of Biological and Agriculture Engineering, Louisiana State University AgCenter, Baton Rouge, LA 70803, USA; Tel: +1 2255781060; Fax: +1 2255783492;

E-mail: CTheegala@agcenter.lsu.edu
}

required. The American Society for Testing and Material (ASTM) and European Standards Organization (EN) have developed specifications, ASTM D6751 and EN 14214 respectively $[7,8]$ to test pure biodiesel (B100) by physical, chromatographic, and spectroscopic methods to apply the standards. ASTM D4951 and EN 14538 methods are used to analyze biodiesel samples for trace metals [9, 10]. The method only requires sodium, potassium, calcium, magnesium, phosphorus, and sulfur since the presence of these metals contaminants can lead to operational problems in vehicle engines. Sodium and potassium hydroxides are important as they are utilized as catalysts in the production process of biodiesel and are removed during the wash process. Presence of these metals in the final product can result in the formation of deposits in the fuel injection system as well as poisoning of emission control aftertreatment systems. Magnesium and calcium, though rarely used as absorbents in the production process, can cause similar problems in vehicle engines as sodium and potassium. Phosphorus can also form deposits and damage the ability of after-treatment systems to reduce exhaust emissions. Sulfur levels in fuel are reduced to $0.0015 \%$ (or $15 \mathrm{mg} / \mathrm{L})$. Biodiesel or their blends are not supposed to exceed this limit. Metals other than those discussed above, are important as further research is conducted to see the effects of additives and chemicals on the physical and chemical characteristics of biodiesel. This method allows for convenient determination of the concentrations of metals in biodiesel samples. This method might be of special interest to environmental laboratories who analyze samples of varying matrices on the same instrument using the same accessories and similar instrument conditions; hence avoiding the use of additional gases to oxidize organic contents in the samples or changing accessories. 


\subsection{Current Practices of Metals Analyses in Biodiesel}

The ASTM 4951 method calls for weighing a portion of sample diluted by mass with mixed xylenes or other solvent. The solutions are introduced to the inductively coupled plasma (ICP) instrument by free aspiration. Increased organic content in the sample can increase carbon build-up on the quartz torch and may affect the performance of the instrument in subsequent samples. Carbon accumulation on the tip of the torch injector tube is a general problem associated with samples containing high levels of organics or organic solvents. Therefore, a nebulizer gas consisting of oxygen, usually $1 \%$ in argon, is used to remove the carbon deposits (method ASTM 4951). A separate sample introduction system, including torch, gas, chamber, nebulizer, and lines, is maintained for such samples. The sample introduction system is generally switched whenever samples other than biodiesel are required to run. This paper is an attempt to reveal that the same instrument conditions and accessories could be used for most samples in aqueous medium where the ICP-optical emission spectroscopy (ICPOES) is the first choice of instrumentation. These findings could hence save time and cost associated with switching the accessories without compromising the response and sensitivity of the instrument. This method is more appropriately devised for biodiesel analysis than petrochemicals analysis.

Edlund et al. 2002 [11] investigated the addition of oxygen to the gases of the ICP to avoid carbon deposits on the torch or to reduce the background emission for the analysis of biodiesel samples. The oxygen addition was found to be useful for the determination of sodium $(\mathrm{Na})$, because of the suppression of the strong molecular bands of carbon compounds close to the intense $\mathrm{Na}$ lines at 588 and $589 \mathrm{~nm}$.

\subsection{Problems in Current Practices}

Due to the immiscible nature of biodiesel in water, a dedicated sample introduction system (torch, spray chamber, sampling probe, and tubing) has to be used for biodiesel samples. The instrument has to be calibrated separately for water and biodiesel samples. This act becomes extremely cumbersome for labs with a large number of samples and a limited number of instruments. In this situation it will be helpful to use a uniform water-based procedure which, regardless of the sample matrix, can be used simultaneously. The high pressure associated with the use of solvents in conventional methods results in gradual accumulation inside the spray-chamber with time, which can cause the plasma to flicker and affect signal stability. Problems associated with the direct introduction of biodiesel or its blends in the ICP plasma include the production of flames leading to destabilization or extinction of the plasma and the deposition of carbon residues on the torch and cone. Regardless of the instrument used, appropriate sample pretreatment is most critical for determining the accuracy of the analysis. Errors associated with this stage will significantly affect the final results. Onyeso 2005a, 2005b [12,13] developed a method for the determination of Manganese (Mn) in gasoline and diesel fuel by ICP-OES after digestion of the samples in a microwave oven and dilution with water before direct aspiration into the plasma.

\section{MATERIAL AND METHODS}

\subsection{Biodiesel Production}

Biodiesel was produced in an automatic biodiesel processor, BioPro 190 (AGR Energy, Chico, CA, USA)). The process involved esterification and transesterification of used canola oil with methanol using $\mathrm{H}_{2} \mathrm{SO}_{4}$ and $\mathrm{KOH}$ as acid and base catalysts, respectively. The oil was filtered through a 400 micron filter before processing. The oils with the free fatty acid content of approximately $2.98 \%$ (determined by acid-base titration) were converted into esters (biodiesel) by a reaction with methanol using acid catalyzed esterification $\left(\mathrm{H}_{2} \mathrm{SO}_{4}\right)$. This reaction was followed by a base-catalyzed transesterification reaction using methanol and $\mathrm{KOH}$ to convert triglycerides (vegetable oil) into fatty acid methyl esters, FAMEs (biodiesel). Methanol and $\mathrm{KOH}$ were mixed to form methoxide which was then introduced to the triglycerides along with vigorous agitation at approximately $60{ }^{\circ} \mathrm{C}$. The reaction mixture was allowed to settle for $20 \mathrm{~h}$. Glycerol was formed as a by-product and was separated from biodiesel, settling at the bottom. The biodiesel product was washed with tap water and filtered sequentially through 10 and 2 micron filters. The final product was tested according to ASTM procedures for total and free glycerin (ASTM D6751).

\subsection{Samples Preparation}

Six sets of B100 samples in triplicate were prepared by weighing $0.25-0.5 \mathrm{~g}$ of biodiesel up to four decimal places into acid-rinsed fluorocarbon digestion vessels. The vessels were supplied with single ported Teflon caps equipped with pressure relief valves to regulate excessive pressure inside the vessels. Approximately $9 \mathrm{~mL}$ of metals grade $\mathrm{HNO}_{3}$ and $1 \mathrm{~mL}$ of metals grade $\mathrm{HCl}$ was added to each vessel. The vessels were then weighed before the digestion. One set of samples was used as a blank B100 while the other sets were used for matrix spike (MS) recovery at five different concentrations (Appendix 1). For B100 spiked samples, a water-based spiking solution (Catalog No. MIXSTD1-5, Spex, Certiprep, USA) was added after the digestion process. The spiking solution contained multiple elements in different concentrations (Appendix 1). The blank B100 samples were used for MS recovery calculations. The purpose of these MS samples was to determine the effect of B100 on the final results at different concentrations and consequent instrument response. A separate concentration verification standards were prepared similarly. Another set of blank B100 samples and oil standards (Catalog No. S23-100Z, Spex, Certiprep, USA) were analyzed using ASTM standard method D495102 [9] where the solutions are introduced to the ICP by free aspiration.

\subsection{Microwave Assisted Acid Digestion}

Microwave Accelerated Reaction System (MARSXpress, CEM Corporation, Matthews, NC) was used to digest the acidified samples. The full power of the system was approximately $1200 \mathrm{~W}$ of microwave energy at a frequency of $2.45 \mathrm{GHz}$. The system was equipped with a 40 -vessel turntable. The instrument was pre-calibrated according to manufacturer specifications. Method parameters of the microwave system were $600 \mathrm{~W}$ power $(100 \%)$, ramped to 
$175^{\circ} \mathrm{C}$ in $5.5 \mathrm{~min}$, hold for $4.5 \mathrm{~min}$, and then cool-down for $1 \mathrm{~h}$.

\subsection{Post-Digestion Samples Treatment}

The samples were weighed after the digestion process to make sure the weight loss was less than $10 \%$ [14]. Approximately $20 \mathrm{~mL}$ of reagent grade deionized water (18 $\mathrm{m} \Omega$ ) was added to each vessel and then transferred to centrifuge tubes. The final volume was brought to $50 \mathrm{~mL}$. A white turbid coloration was observed at this point due to alcohol formed as a result of ester hydrolysis. A clear solution was obtained by centrifugation at approximately $1000 \mathrm{rpm}$ for five min. To be able to run through the ICPOES by pneumatic nebulization, turbidity values less than 1 NTU (nephelometric turbidity unit) are preferred [15]. The digested solution was stable over considerable period of time without change in color, matrix, or concentration of most of the metals.

\subsection{Instrument Setup and Calibration}

All analyses in this study were performed using Varian Vista MPX simultaneous inductively coupled plasma optical emission spectrometer (ICP-OES) with axially viewed plasma. The instrument was equipped with a mass flow controller on the nebulizer gas and 3-channel peristaltic pump. The system was optimized for best performance. The instrument operation parameters are given in Table $\mathbf{1}$.

Table 1. Instrument Operating Conditions

\begin{tabular}{|l|l|}
\hline Power & $1.10 \mathrm{~kW}$ \\
\hline Plasma gas supply: & Argon, ultra high pure (99.99\%) \\
\hline Plasma gas flow: & $15.0 \mathrm{~L} / \mathrm{min}$ \\
\hline Auxiliary gas flow: & $0.75 \mathrm{~L} / \mathrm{min}$ \\
\hline Nebulizer gas flow: & $0.75 \mathrm{~L} / \mathrm{min}$ \\
\hline Nebulizer type: & $\begin{array}{l}\text { SeaSpray/Ezyfit Glass Concentric } \\
\text { Glass Expansion, Melbourne, } \\
\text { Australia). }\end{array}$ \\
\hline Spray Chamber: & Cyclonic twister, Varian Inc. \\
\hline Torch: & Axial, high-solids, Varian Inc. \\
\hline Pump speed: & $15 \mathrm{rpm}$ \\
\hline Sample Delay: & $40 \mathrm{~s}$ \\
\hline Rinse time: & $15 \mathrm{~s}$ between each sample \\
\hline Replicate read time: & $15 \mathrm{~s}$ \\
\hline Instrument stabilization delay: & $10 \mathrm{~s}$ \\
\hline Replicates: & 3 \\
\hline Background correction: & Fitted \\
\hline Correction type: & Point sum \\
\hline Autosampler: & SPS-3, Varian Australia Pty Ltd \\
\hline
\end{tabular}

Since this method was an attempt to analyze biodiesel samples alongside other environmental samples, water-based multi-element calibration standard curves were prepared in $5 \%$ nitric acid and DI water using certified standard solutions (Spex Certiprep, Metuchen, NJ, USA). Most of the elements were analyzed at two or three different wavelengths to differentiate the instrument response at lower or higher concentrations. A seven point calibration curve is was run using different concentrations for different elements based on the values normally expected in environmental matrices. Table 2 shows correlation coefficient values $\left(R^{2}\right)$ and instrument detection limits as obtained for all the elements which were significant at values greater than 0.995 .

\subsection{Instrument Detection Limits (IDL)}

The water-based IDLs were determined as three times the standard deviation (SD) of seven replicates of a concentration verification standard (Spex Certiprep, Metuchen, NJ, USA) at concentrations $3-5$ times the manufacturer's IDL on three non-consecutive days [16]. The biodiesel-based IDLs were determined by digesting at least seven aliquots of B100 samples as mentioned above. A water-based spiking solution containing a concentration verification standard at concentrations $3-5$ times the manufacturer's IDL were added before bringing the samples up to $50 \mathrm{~mL}$ final volume. IDLs were then calculated as $3 \mathrm{xSD}$ on three non-consecutive days.

\subsection{Precision and Accuracy}

Relative percent deviation (RSD) for replicate analyses of the same sample were obtained as RSD $=$ (standard deviation/mean value) x 100. The RSD values for replicate measurements of a sample were obtained from the Expert Software supplied with the ICP.

For matrix spike recovery, results for all the spiked samples were adjusted to exactly $0.5000 \mathrm{~g}$ of B100 and 50 $\mathrm{mL}$ post-digestion final volume. Recovery was then calculated as:

$\%$ Recovery $=$ (conc. in spiked sample - conc. in unspiked sample/actual spike conc.) x100

Calculations: Final concentration of element in B100 samples was calculated as:

Concentration of element in B100 $(\mathrm{mg} / \mathrm{kg})=$ Conc. $(\mathrm{mg} / \mathrm{L}) \mathrm{x}$ Vol. $(\mathrm{L}) / W(\mathrm{~kg})$

where Conc. is the concentration of the element obtained by ICP in $\mathrm{mg} / \mathrm{L}, \mathrm{Vol}$. is the final volume of the digested solution in liters, and $W$ is the weight of the B100 sample in $\mathrm{kg}$.

\section{RESULTS AND DISCUSSION}

The acceptable weight loss $(<10 \%$ of the whole digestate including sample, $\mathrm{HNO}_{3}$ and $\mathrm{HCl}$ solution mentioned in section 2.2, sample preparation) during sample digestion indicated that a microwave assisted acid digestion system equipped with a pressure release vent can be utilized for elemental analyses [14] of B100 biodiesel. The graph in Fig. (1) shows that reducing the sample weight from $0.5 \mathrm{~g}$ to $0.25 \mathrm{~g}$ reduces the weight lost during digestion process $\left(\mathrm{R}^{2}=\right.$ 0.86 ). The weight loss is affected by different factors including the amount of organic carbon present in the sample, pressure exerted on the vessel's vent, and torque applied to close the caps on digestion vessels. Therefore, a linear trend was not established while increasing the sample weight. Lower sample weight reduced the weight loss, however, minimum detectable concentrations of trace elements in final solutions or biodiesel would be affected. The digested samples were homogenously diluted with 
Table 2. Initial Instrument Calibration and Instrument Detection Limits

\begin{tabular}{|c|c|c|c|c|c|c|c|c|}
\hline $\begin{array}{l}\text { Element and } \\
\text { Wavelength }\end{array}$ & $\begin{array}{l}\text { IDL Water- } \\
\text { Based, } \mu \mathrm{g} / \mathrm{L}\end{array}$ & $\begin{array}{c}\text { Std. Curve } \\
\text { Correlation } \\
\text { Coefficient, } \mathbf{R}^{2}\end{array}$ & $\begin{array}{l}\text { Element and } \\
\text { Wavelength }\end{array}$ & $\begin{array}{l}\text { IDL Water- } \\
\text { Based, } \mu \mathrm{g} / \mathrm{L}\end{array}$ & $\begin{array}{c}\text { Std. Curve } \\
\text { Correlation } \\
\text { Coefficient, } \mathbf{R}^{2}\end{array}$ & $\begin{array}{l}\text { Element and } \\
\text { Wavelength }\end{array}$ & $\begin{array}{l}\text { IDL Water- } \\
\text { Based, } \mu \mathrm{g} / \mathrm{L}\end{array}$ & $\begin{array}{c}\text { Std. Curve } \\
\text { Correlation } \\
\text { Coefficient, } \mathbf{R}^{2}\end{array}$ \\
\hline Ag 328.068 & 2.9 & 0.9999 & K 769.897 & 34.6 & 0.9909 & S 181.972 & 2.5 & 0.9998 \\
\hline Al 236.705 & 15.1 & 0.9994 & Mg 279.078 & 5.4 & 0.9989 & S 182.562 & 5.1 & 0.9999 \\
\hline Al 396.152 & 2.0 & 0.9989 & $\operatorname{Mg} 279.553$ & 4.5 & 0.9977 & $\mathrm{Sb} 206.834$ & 4.0 & 0.9998 \\
\hline As 188.980 & 1.3 & 0.9998 & $\operatorname{Mg} 280.270$ & 3.3 & 0.9992 & Se 196.026 & 10.4 & 0.9999 \\
\hline As 234.984 & 14.6 & 0.9999 & Mn 257.610 & 0.3 & 0.9991 & Si 251.611 & 15.5 & 0.9983 \\
\hline Be 313.042 & 0.2 & 0.9990 & Mo 202.032 & 0.1 & 0.9991 & Sn 189.927 & 1.7 & 0.9986 \\
\hline Ca 396.847 & 23.1 & 0.9967 & $\mathrm{Na} 568.821$ & 401.1 & 0.9981 & $\mathrm{Sr} 407.771$ & 4.1 & 0.9981 \\
\hline Cd 226.502 & 0.3 & 0.9987 & Na 588.995 & 27.5 & 0.9992 & Th 288.505 & 5.4 & 0.9994 \\
\hline Co 228.615 & 0.5 & 0.9987 & Na 589.592 & 35.6 & 0.9928 & Tl 190.794 & 3.4 & 0.9986 \\
\hline Co 238.892 & 0.5 & 0.9987 & Ni 230.299 & 1.3 & 0.9987 & V 292.401 & 0.3 & 0.9993 \\
\hline Cr 267.716 & 0.3 & 0.9991 & Ni 231.604 & 1.0 & 0.9987 & Y 360.074 & 0.2 & 0.9994 \\
\hline $\mathrm{Cu} 324.754$ & 1.1 & 0.9997 & Р 213.618 & 0.8 & 0.9997 & Y 371.029 & 0.2 & 0.9994 \\
\hline $\mathrm{Cu} 327.395$ & 0.5 & 0.9997 & Р 214.914 & 2.9 & 0.9997 & Zn 202.548 & 2.2 & 0.9983 \\
\hline $\mathrm{Fe} 238.204$ & 24.8 & 0.9989 & $\mathrm{~Pb} 220.353$ & 1.9 & 0.9973 & Zn 206.200 & 2.5 & 0.9985 \\
\hline Fe 259.940 & 26.0 & 0.9992 & $\mathrm{~Pb} 283.305$ & 8.3 & 0.9988 & Zn 213.857 & 2.0 & 0.9995 \\
\hline K 766.491 & 38.8 & 0.9982 & & & & & & \\
\hline
\end{tabular}

deionized water or water-based spiking solution before bring up to final volume. A white turbid solution resulted from alcohol formation due to hydrolysis of esters. Acid catalyzed hydrolysis of esters yields carboxylic acid and alcohol [17]. Because the reaction is reversible, an excess of water is used to move the equilibrium forward towards the hydrolysis products as shown here:

$\mathrm{RCOOR}^{\prime}+\mathrm{H}_{2} \mathrm{O} \rightarrow \mathrm{RCOO}^{-}+\mathrm{H}^{+}+\mathrm{R}^{\prime} \mathrm{OH}$

Esters water acid catalyst carboxylic acid alcohol

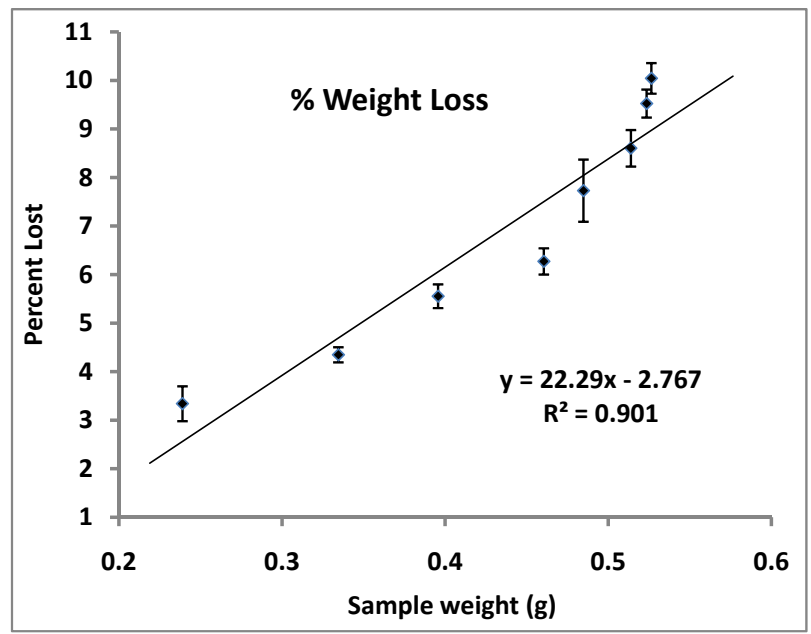

Fig. (1). Weight loss during digestion process as a function of initial weight of sample aliquot taken.

Formation of alcohols and their release decrease the overall carbon content of the ester molecule, thus making it easy on the sample delivery system, particularly the torch.
The centrifugation process rapidly clears the white turbid solution leaving a solution with turbidity values less than 1 NTU (0.08 to 0.14 NTU), generally appropriate for ICP analyses. This decrease in turbidity can also be accomplished by leaving the solution undisturbed for several hours under ambient temperature. The process, however, is extremely slow. The viscosity of this solution was comparable to that of a 5\% nitric acid solution in water, suggesting the suitability of water-based digestate of B100 for aspiration in the ICP.

Visual inspection of the ICP torch indicated insignificant carbon deposition comparable to that caused by other environmental samples run at an environmental analytical lab. No unusual operation of the plasma, spray chamber, or sample introduction system was detected. A $100 \%$ waterbased standard was run before and after B100 analyses to see any significant shift in the response of the instrument. Both readings for all the elements were in $100 \pm 1 \%$ range except molybdenum, selenium, and strontium which were in $100 \pm 3 \%$ range. The RSD values were less than $5 \%$. Thus no significant trend of increasing or decreasing concentrations was observed for any of the elements. Signal-to-background ratio (SBR) for S $182.562 \mathrm{~nm}$ line in blank deionized water, for instance, was 0.032 before running B100 samples and 0.030 after the run. Similarly, for P $214.914 \mathrm{~nm}$ line the SBR was 0.006 and 0.005 before and after the B100 samples, respectively. A stable response of the instrument was indicated by SBRs of selected elements in a $5 \mathrm{mg} / \mathrm{L}$ standard analyzed before and after the B100 samples. Most elements show less than a $10 \%$ change in the SBR ratio (Table 3). This result bears particular significance for suitability of the method using the same instrument and the same sample 
Table 3. Change in Signal-to-Background Ratios (SBR) of Selected Elememnts in a 5 mg/L Aqueous Standard; before and after Running B100 Spiked Samples

\begin{tabular}{|c|c|c|c|c|c|c|c|}
\hline Element & Before & After & $\%$ Change & Element & Before & After & $\%$ Change \\
\hline $\mathrm{Al} 236.705$ & 2.308 & 2.534 & $10 \%$ & Mn 257.610 & 218.622 & 211.9465 & $-3 \%$ \\
\hline Al 396.152 & 9.817 & 10.7445 & $9 \%$ & Ni 230.299 & 26.602 & 27.187 & $2 \%$ \\
\hline As 188.980 & 12.463 & 13.2065 & $6 \%$ & Ni 231.604 & 32.299 & 32.777 & $1 \%$ \\
\hline As 234.984 & 2.046 & 2.2235 & $9 \%$ & $\mathrm{~Pb} 283.305$ & 1.73 & 1.8775 & $9 \%$ \\
\hline $\mathrm{Ba} 455.403$ & 117.967 & 122.392 & $4 \%$ & S 181.972 & 0.171 & 0.1705 & $0 \%$ \\
\hline $\mathrm{Cd} 214.439$ & 156.706 & 159.904 & $2 \%$ & S 182.562 & 0.017 & 0.017 & $0 \%$ \\
\hline Cr 267.716 & 61.651 & 62.986 & $2 \%$ & Th 288.505 & 0.091 & 0.0875 & $-4 \%$ \\
\hline $\mathrm{Cu} 324.754$ & 26.774 & 29.1675 & $9 \%$ & T1 337.280 & 0.008 & 0.008 & $0 \%$ \\
\hline $\mathrm{Cu} 327.395$ & 18.531 & 20.8925 & $13 \%$ & Zn 202.548 & 112.015 & 113.314 & $1 \%$ \\
\hline K 766.491 & 42.721 & 41.6565 & $-2 \%$ & Zn 206.200 & 45.036 & 44.53 & $-1 \%$ \\
\hline K 769.897 & 37.214 & 37.3615 & $0 \%$ & Zn 213.857 & 124.548 & 117.2985 & $-6 \%$ \\
\hline
\end{tabular}

introduction system for one environmental matrix without compromising the sensitivity for others.

The instrument detection limits for water-based samples was one to several fold lower than those determined using blank B100-based samples (Appendix 1). Elements like Ca, $\mathrm{Mg}, \mathrm{P}$, and $\mathrm{S}$, were present at trace concentration as contaminants in biodiesel samples. The catalyst used in the production process, $\mathrm{K}$ or $\mathrm{Na}$, has lower IDLs in biodieselbased samples. Overall, the IDLs indicated that the method can be used to detect concentrations significantly lower than those specified under ASTM 6751 for B100 biodiesel. For potassium determination, wavelength line K $769.897 \mathrm{~nm}$ has better detection and sensitivity at lower or higher levels compared to K $766.491 \mathrm{~nm}$. No significant interference was observed except the matrix background concentrations. Based on the IDLs, the minimum detectable concentration (MDC) of $\mathrm{K}$ in biodiesel is approximately $3 \mathrm{mg} / \mathrm{L}$ for a final digestate volume of $50 \mathrm{~mL}$. However, lowering the final digestate volume lowers the MDC; for instance, $1.5 \mathrm{mg} / \mathrm{L}$ in $25 \mathrm{~mL}$. Lower levels are possible through further concentrating the digestate. The term MDC mentioned here is the calculated final concentration of an element in the matrix, i.e. biodiesel, as determined by digesting a small sample aliquot diluted to a definite digestate volume for running though ICP-OES. Hence, examining MDCs and IDLs are helpful in determining the final digestate volumes. Currently, the ASTM and European Union standards [7, 8] for $\mathrm{Na}$ and $\mathrm{K}$ combined, is $5 \mathrm{mg} / \mathrm{L}$. This was achieved by using K 766.491 together with $\mathrm{Na} 588.995 \mathrm{~nm}$ line. The $\mathrm{Na}$ $588.995 \mathrm{~nm}$ line has a lower MDC of approximately $2 \mathrm{mg} / \mathrm{L}$ compared to other $\mathrm{Na}$ lines $(\mathrm{Na} 589.592 \mathrm{~nm}$ and $\mathrm{Na} 568.821$ $\mathrm{nm}$ with MDCs as 4 and $36 \mathrm{mg} / \mathrm{L}$, respectively). Resolution and intensity for $\mathrm{Na} 568.821 \mathrm{~nm}$ line was low. Similarly, the EN 14214 standard for $\mathrm{Ca}$ and $\mathrm{Mg}$ combined is $5 \mathrm{mg} / \mathrm{L}$. Fuel injection equipment manufacturers have proposed to limit the content of $\mathrm{Na}+\mathrm{K}$ and $\mathrm{Ca}+\mathrm{Mg}$ to $5 \mathrm{mg} / \mathrm{L}$ each [18]. $\mathrm{Ca}$ was noted for high background concentrations. We used two lines for Ca: $\mathrm{Ca} 317.933 \mathrm{~nm}$ and $\mathrm{Ca} 396.847 \mathrm{~nm}$. The latter was found suitable for low values and high intensity. Approximately similar IDLs were obtained for the lines, however, Ca $317.933 \mathrm{~nm}$ was found more sensitive to higher concentrations. The study suggested suitability of $\mathrm{Ca}$ $396.933 \mathrm{~nm}$ for biodiesel analyses. The MDC for this line was approximately $3 \mathrm{mg} / \mathrm{L}$ based on the final volume of 50 $\mathrm{mL}$ which can be reduced by lowering the final volume. $\mathrm{Mg}$ $279.078 \mathrm{~nm}$ line was found to be sensitive compared to $\mathrm{Mg}$ $280.270 \mathrm{~nm}$. Both have approximately $2 \mathrm{mg} / \mathrm{L}$ MDCs. The $\mathrm{Ca}+\mathrm{Mg}$ combined $5 \mathrm{mg} / \mathrm{L}$ standard is hence achievable.

Phosphorus concentration was easily detectable at significantly lower levels. Two lines, P $213.618 \mathrm{~nm}$ and P $214.914 \mathrm{~nm}$, were used in the current study. Both lines were sensitive to lower and higher concentrations. The IDLs were 0.002 and $0.005 \mathrm{mg} / \mathrm{L}$ with $\mathrm{MDCs}$ as 0.2 and $0.5 \mathrm{mg} / \mathrm{L}$, respectively. Mo $213.606 \mathrm{~nm}$ has an insignificant interference with P $213.618 \mathrm{~nm}$, while no interference was observed for P 214.914. The ASTM standard for P in B100 is $0.001 \%$ by mass, i.e., $10 \mathrm{mg} / \mathrm{L}$ (ASTM D6751).

Because of environmental consequences, the ASTM standard for sulfur content in fuel is reduced to $15 \mathrm{mg} / \mathrm{L}$ (ASTM D6751). This standard is easily determined by the current procedure. Two lines, S $181.972 \mathrm{~nm}$ and S 182.562 $\mathrm{nm}$, were used. Both were sensitive to low and high 
concentrations with IDLs of $0.006 \mathrm{mg} / \mathrm{L}$ and MDCs as 0.6 $\mathrm{mg} / \mathrm{L}$. S 182.562 has spectral interference with Boron 182.577, therefore, S 181.972 is preferred (Fig. 2).

Results of metals concentration in blank B100 samples and oil standards obtained with ASTM standard method D4951-02 [9] were recovered in 100 $3 \%$ range.

\subsection{Matrix Spike Recovery}

Correlation coefficient values $\left(\mathrm{R}^{2}\right)$ of all the elements in the matrix spiked samples were greater than 0.99 except $\mathrm{Ca}$, $\mathrm{Sn}$, and K $769.897 \mathrm{~nm}$, which were greater than 0.98 . The $\mathrm{R}^{2}$ values for two of the $\mathrm{Na}$ lines, $\mathrm{Na} 588.995 \mathrm{~nm}$ and $\mathrm{Na}$ $589.592 \mathrm{~nm}$, were greater than 0.96 but less than 0.98 . Values for $\mathrm{Ag}$ and $\mathrm{Sr}$ were 0.93 and 0.89 , respectively. Significant correlation coefficient values observed by the spiked samples indicated that aqueous standard calibration curves are sufficient for analyzing both water and digested B100 samples.

Some of the elements were detected at trace levels or as contaminants in the B100 (Appendix 1). The IDLs for these elements were, therefore, higher for the B100 matrix than water. These background concentrations in turn affected the recovery of low concentration spikes, resulting in $100 \pm 10 \%$ for $81 \%$ of the elements while $92 \%$ of the elements had $100 \pm 20 \%$ recovery. The middle-range spike standards (MS\#3) had a recovery of $100 \pm 20 \%$ for $98 \%$ of the elements and $100 \pm 10 \%$ for $87 \%$ of the elements. Higher-range spiked standards (MS\#4 and 5) have a significant recovery of $97 \pm 7 \%$ for $95 \%$ of the elements. Overall recovery for all the elements was noted at $100 \pm 11 \%$, meeting the quality control objective under most of the analytical methods. Fig. (3) shows matrix spike recovery of all the elements determined at different spike concentrations. Accuracy and performance of the method is obvious by the mean recovery shown in the graph. Outliers were noted for one or more lines of $\mathrm{Al}, \mathrm{Ca}$, $\mathrm{Mg}, \mathrm{Na}$, and $\mathrm{Sr}$ due to background concentrations in the matrix discussed above.

The study shows that yttrium can be successfully used as an internal standard wherever required. Recovery was $101 \pm 3 \%$ and $102 \pm 2 \%$ for Y $360.074 \mathrm{~nm}$ and Y $371.029 \mathrm{~nm}$ lines, respectively. Final results obtained can be corrected for recovery of internal standard. This would maximize the performance of the analyses and correct for differences in aerosol transport efficiencies.

The method was primarily tested on B100 biodiesel meeting the ASTM specifications. Biodiesel not meeting ASTM specifications may contain free glycerol, soap, and any unreacted alkali metals which are fully or partially miscible in water and should have negligible impact on the sensitivity of the method. However, bound glycerol (mono-, di-, and triglycerides) is reported for microwave irradiated transesterification reactions, such as alcoholysis/glycerolysis to yield FAMEs in the presence of methanol in the reaction mixture [19]. Acid hydrolysis of triglycerides is expected to yield glycerin and free fatty acids during the digestion process [20]. Long chain FFAs are fairly miscible in water, however, the solubility of FFAs, especially those with long chains, increases with increasing temperature higher than about $160{ }^{\circ} \mathrm{C}$, forming a regular solution containing the FFAs [21]. This was true in our case. No phase separation or any change in the digestive solution was observed with storage at room temperature for several months.

\subsection{Precision of the Method}

Precision of the method is displayed in Fig. (4). The mean RSD for the majority of the elements is under $5 \%$, while the overall mean RSDs are less than $15 \%$. Precision increased with increasing metal concentrations in the matrix

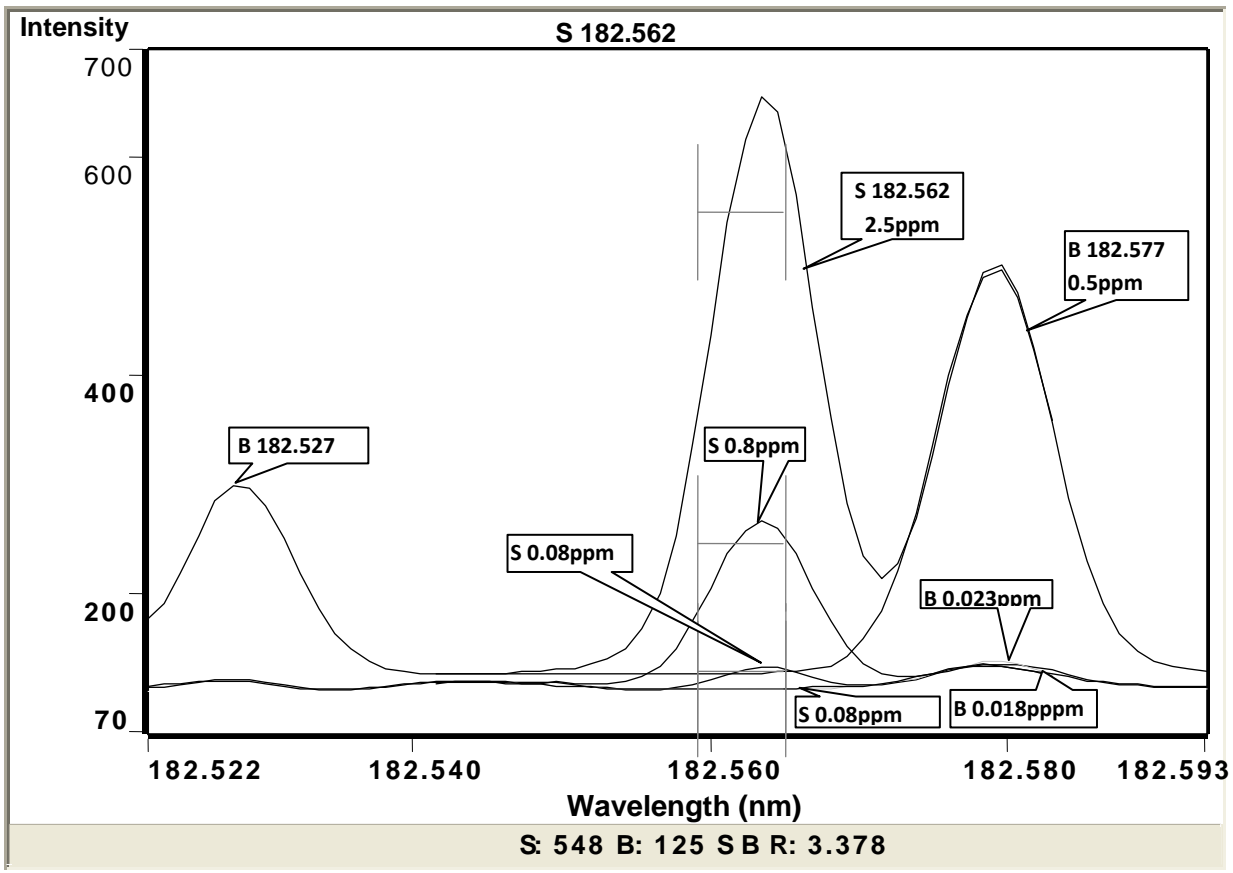

Fig. (2). Graph showing spectral interference of Boron line B $182.577 \mathrm{~nm}$ with Sulfur line S $182.562 \mathrm{~nm}$. Label shows line used and/or concentrations in parts per million (ppm, $\mathrm{mg} / \mathrm{L}$ ). 


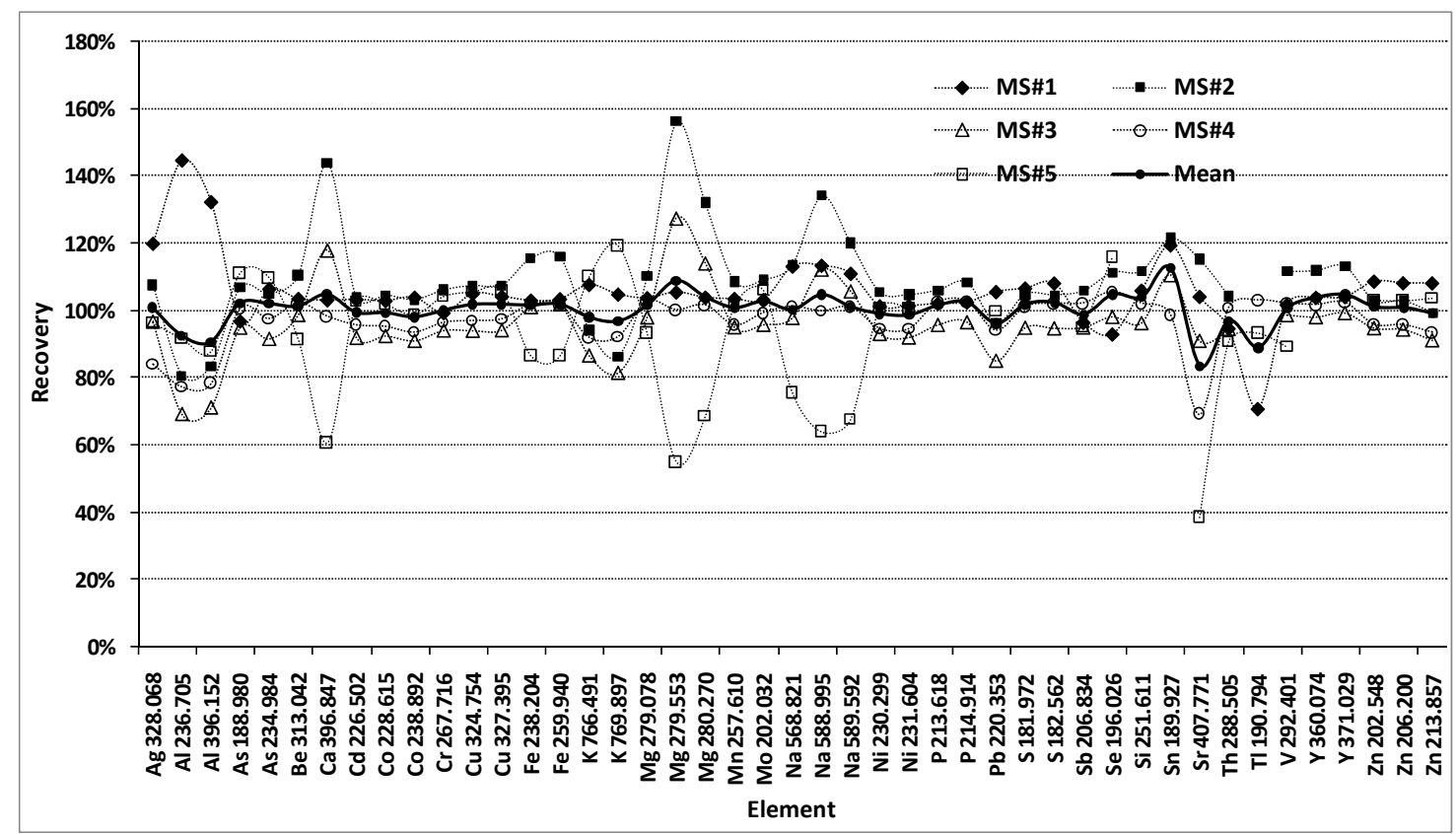

Fig. (3). Matrix spike (MS) recovery of the elements studied.

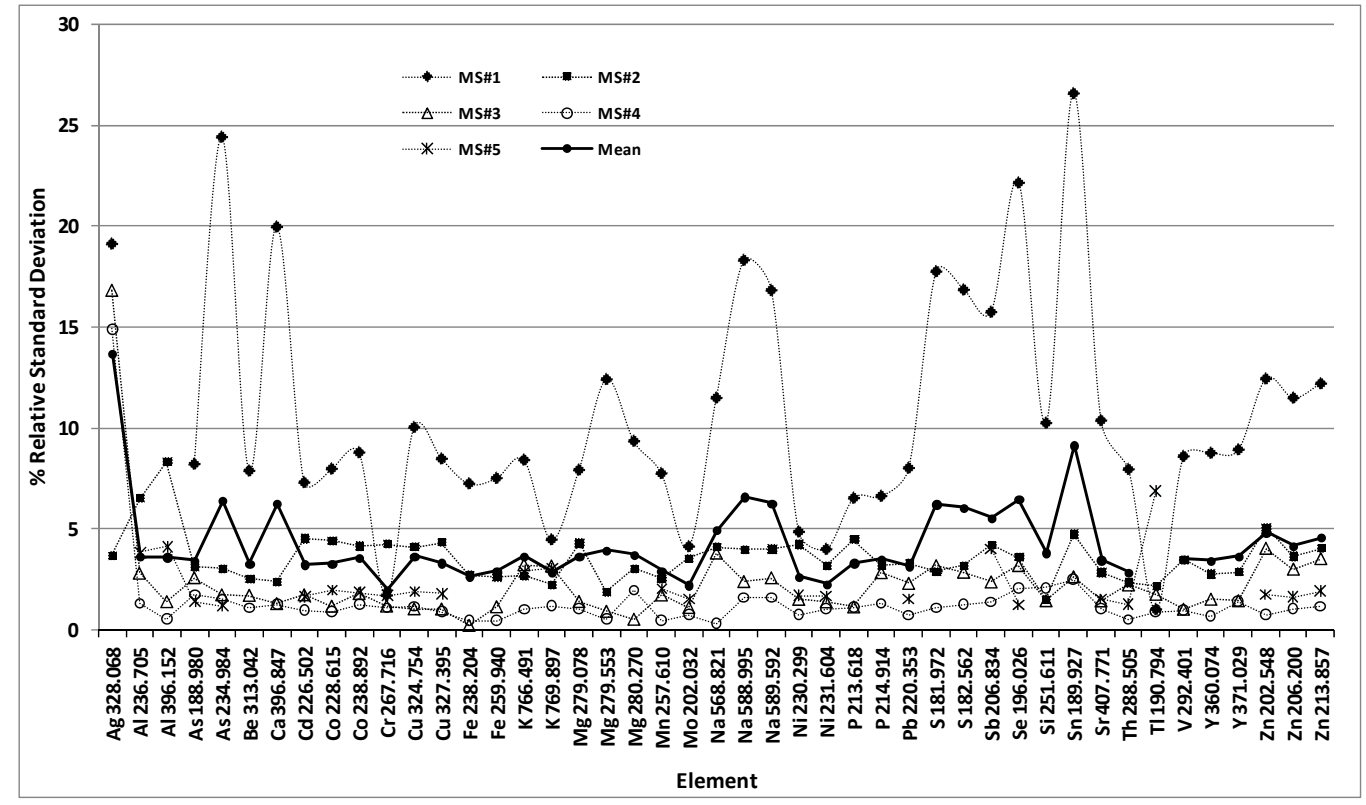

Fig. (4). Relative standard deviation (RSD) for replicate analysis of matrix spiked samples and their mean values.

spike or the samples. As expected, the least concentrated matrix spikes have the highest RSDs, while the highest ones have the lowest RSDs. Thus for some elements at extremely lower concentrations (MS\#1) with RSD $>20 \%$, the performance of the method seems to be compromised.

Precision of the instrument as indicated by RSD of three replicate readings, showed that approximately $90 \%$ of the measurements have RSD values less than $2.7 \%$, while $99 \%$ of the measurements were below $13.1 \%$. High variability for low concentrated samples was successfully reduced by utilizing a rinse time of more than $15 \mathrm{~s}$ between samples. The $15 \mathrm{~s}$ rinse time was, however, sufficient for middle and higher concentration samples to avoid memory interference to an insignificant level. Viscosity and turbidity have an effect on precision and instrument stability [11]. Kinematic viscosity of post-digestion solutions matched with digested water blanks at $25{ }^{\circ} \mathrm{C}$ i.e. approximately 1.00 to 0.94 centistokes, respectively, reducing matrix effects in the sample introduction system. Turbidity of all the solutions ranged between $0.08 \sim 0.14$ NTU. Low turbidity of the postdigestion solution means low dissolved solids and negligible salt buildup at the nebulizer tip, thus improving the aerosol flow rate.

Sample size has an effect on the weight lost during the digestion process. Reducing the sample size from $0.5 \mathrm{~g}$ to $0.25 \mathrm{~g}$ reduces the weight lost (Fig. 1). If the concentration of element(s) of concern in the final digestate solution is not compromised, the lowest possible weight of the sample is 
recommended. The sample size can be more precisely calculated from IDLs, MDCs, and the final volume of the digestate solution. This calculation should be based on an element of concern expected to be present in the lowest concentration while selecting a wavelength line more sensitive to trace levels. Another way to reduce the weight lost during the digestion process is sample pretreatment. Before digesting the sample in a microwave reaction system, the sample can be predigested in a hood for at least 15 minutes until the reaction stops.

Accuracy of the method determined by matrix spike recovery indicated sustained concentrations of the elements in the digested B100 samples. The study shows that the biodiesel matrix has no effect on the performance of the overall analyses and vice versa. There is no reference metal standard available in a FAMEs-base (biodiesel-base) to further evaluate the method. Therefore, the aqueous standards were added after the digestion process to obtain B100 matrix spiked samples. The samples were hence treated as environmental samples of sufficient organic loading. Significant correlation coefficient values observed by the spiked samples indicated that aqueous standard calibration curves are sufficient to analyze both water and digested $\mathrm{B} 100$ samples.

\section{CONCLUSION}

The current study revealed that the same instrumental conditions are sufficient to analyze aqueous samples concurrently with biodiesel (B100) samples without compromising the performance of the instrument or overall analysis. The method, therefore, help save time and cost associated with additional accessories and facilitating quick turnaround. The study shows that microwave assisted acid digestion can be employed to prepare biodiesel samples for metals analysis using ICP-OES. Biodiesel and its analysis are gaining significant potential especially for analytical community. This study, hence, proves an important addition to understand the analytical aspects of biodiesel B100.

\section{APPENDIX 1}

Biodiesel-Based (B100); Instrument Detection Limits (IDLs); Matrix Spike (MS) Concentrations and Recovery; and Relative Standard Deviation (RSD) Values

\begin{tabular}{|c|c|c|c|c|c|c|c|c|c|c|c|c|c|c|c|c|c|c|c|c|c|c|c|}
\hline Element & \begin{tabular}{|c|} 
IDLs \\
Biodiesel \\
Based, ppb
\end{tabular} & $\begin{array}{c}\mathbf{R}^{2}, \\
\mathbf{B 1 0 0}\end{array}$ & \begin{tabular}{|c|} 
Conc. \\
in \\
B100, \\
ppm \\
\end{tabular} & \begin{tabular}{|c|} 
MS\#1 \\
Conc. \\
ppm
\end{tabular} & $\begin{array}{c}\text { MS } \\
\text { Recovery }\end{array}$ & $\begin{array}{c}\text { RSD } \\
\text { Replicate } \\
\text { Analyses }\end{array}$ & \begin{tabular}{|c|} 
Average \\
RSD Off- \\
Instrumen \\
$\mathbf{t}$ \\
\end{tabular} & \begin{tabular}{c|} 
MS\#2 \\
conc. \\
ppm
\end{tabular} & \begin{tabular}{|c} 
MS \\
Recovery
\end{tabular} & \begin{tabular}{|c|} 
RSD \\
Replicate \\
analyses
\end{tabular} & $\begin{array}{c}\text { Average } \\
\text { RSD off- } \\
\text { Instrument }\end{array}$ & $\begin{array}{c}\text { MS\#3 } \\
\text { conc. } \\
\text { ppm }\end{array}$ & $\mid \begin{array}{c}\text { MS } \\
\text { Recovery }\end{array}$ & $\begin{array}{c}\text { RSD } \\
\text { Replicate } \\
\text { Analyses }\end{array}$ & \begin{tabular}{|c|c|} 
Average \\
RSD off- \\
Instrume \\
nt
\end{tabular} & \begin{tabular}{|c|} 
MS\#4 \\
conc. \\
ppm
\end{tabular} & $\mid \begin{array}{c}\text { MS } \\
\text { Recovery }\end{array}$ & \begin{tabular}{|c|} 
RSD \\
Replicate \\
Analyses
\end{tabular} & \begin{tabular}{|c|} 
Average \\
RSD off- \\
Instrument
\end{tabular} & $\begin{array}{l}\text { MS\#5 } \\
\text { conc. } \\
\text { ppm }\end{array}$ & $\begin{array}{c}\text { MS } \\
\text { Recovery }\end{array}$ & \begin{tabular}{|c|} 
RSD \\
Replicate \\
Analyses
\end{tabular} & $\begin{array}{c}\text { Average } \\
\text { RSD Off- } \\
\text { Instrument }\end{array}$ \\
\hline Ag 328.068 & 4.9 & 0.9368 & \begin{tabular}{|l|l|} 
\\
\end{tabular} & \begin{tabular}{|l|l|}
0.008 \\
\end{tabular} & $120.0 \%$ & 19.1 & 7.1 & \begin{tabular}{|l|}
0.16 \\
\end{tabular} & $107.6 \%$ & 3.7 & 1.1 & \begin{tabular}{|l|}
0.32 \\
\end{tabular} & $96.8 \%$ & 16.8 & 1.5 & 0.4 & $84.2 \%$ & 14.9 & 1.4 & 0.5 & $96.5 \%$ & -6.2 & 9.7 \\
\hline Al 236.705 & 17.1 & 0.9926 & \begin{tabular}{|l|}
0.2429 \\
\end{tabular} & \begin{tabular}{|l|l|}
0.036 \\
\end{tabular} & $144.7 \%$ & 92.2 & 1.2 & \begin{tabular}{|l|}
0.36 \\
\end{tabular} & $80.7 \%$ & 6.5 & 1.8 & \begin{tabular}{|l|}
0.72 \\
\end{tabular} & $69.3 \%$ & 2.8 & 2.2 & 1.8 & $77.5 \%$ & 1.3 & 0.9 & 5.0 & $91.8 \%$ & 3.9 & 1.3 \\
\hline Al 396.152 & 6.8 & \begin{tabular}{|l|l|} 
\\
\end{tabular} & \begin{tabular}{|l|l|}
0.3016 \\
\end{tabular} & \begin{tabular}{|l|}
0.036 \\
\end{tabular} & $132.3 \%$ & 106.5 & 0.7 & \begin{tabular}{|l|}
0.36 \\
\end{tabular} & $83.6 \%$ & 8.3 & 1.1 & \begin{tabular}{|l|}
0.72 \\
\end{tabular} & $71.3 \%$ & 1.4 & 1.5 & 1.8 & $78.4 \%$ & 0.5 & 1.0 & 5.0 & $88.0 \%$ & 4.2 & 1.8 \\
\hline As 188.980 & 5.7 & 0.9948 & \begin{tabular}{|l|l|}
0.0041 \\
\end{tabular} & \begin{tabular}{|l|}
0.036 \\
\end{tabular} & $97.0 \%$ & 8.2 & 5.5 & \begin{tabular}{|l|}
0.36 \\
\end{tabular} & $106.8 \%$ & 3.1 & 2.3 & \begin{tabular}{|l|}
0.72 \\
\end{tabular} & $95.0 \%$ & 2.6 & 1.2 & 1.8 & $100.7 \%$ & 1.7 & 1.4 & 5.0 & $111.4 \%$ & 1.5 & 1.4 \\
\hline As 234.984 & 18.2 & 0.9945 & \begin{tabular}{|l|l|}
0.0546 \\
\end{tabular} & \begin{tabular}{|l|}
0.036 \\
\end{tabular} & $106.5 \%$ & 24.4 & 7.5 & \begin{tabular}{|l|}
0.36 \\
\end{tabular} & $105.0 \%$ & 3.0 & 2.6 & \begin{tabular}{|l|}
0.72 \\
\end{tabular} & $91.7 \%$ & 1.7 & 1.7 & 1.8 & $97.6 \%$ & 1.5 & 1.4 & 5.0 & $109.9 \%$ & 1.2 & 1.7 \\
\hline Be 313.042 & 0.1 & 0.9980 & \begin{tabular}{|l|l|}
0.0007 \\
\end{tabular} & \begin{tabular}{|l|}
0.008 \\
\end{tabular} & \begin{tabular}{|l|l|}
$103.6 \%$ \\
\end{tabular} & 7.9 & 1.2 & \begin{tabular}{|l|l|}
0.08 \\
\end{tabular} & $110.5 \%$ & 2.5 & 1.1 & \begin{tabular}{|l|}
0.16 \\
\end{tabular} & $98.8 \%$ & 1.7 & 2.2 & 0.4 & $102.3 \%$ & 1.1 & 1.9 & 1.0 & $91.5 \%$ & - & - \\
\hline Ca 396.847 & 34.2 & 0.9848 & \begin{tabular}{|l|l|}
1.402 \\
\end{tabular} & \begin{tabular}{|l|}
0.800 \\
\end{tabular} & \begin{tabular}{|l|l|}
$103.2 \%$ \\
\end{tabular} & 20.0 & 1.1 & \begin{tabular}{|l|l|}
8.00 \\
\end{tabular} & $143.9 \%$ & 2.4 & 1.6 & 16.00 & $118.0 \%$ & 1.3 & 1.4 & 40.0 & $98.3 \%$ & 1.3 & 0.9 & 100.0 & $60.9 \%$ & -10.3 & 1.0 \\
\hline $\mathrm{Cd} 226.502$ & 1.1 & 0.9976 & \begin{tabular}{|l|l|}
0.0022 \\
\end{tabular} & \begin{tabular}{|l|}
0.036 \\
\end{tabular} & \begin{tabular}{|l|l|}
$103.4 \%$ \\
\end{tabular} & 7.3 & 0.9 & \begin{tabular}{|l|}
0.36 \\
\end{tabular} & $103.7 \%$ & 4.5 & 0.8 & \begin{tabular}{|l|}
0.72 \\
\end{tabular} & $92.0 \%$ & 1.7 & 2.3 & 1.8 & $95.8 \%$ & 1.0 & 1.3 & 5.0 & $102.9 \%$ & 1.7 & 1.6 \\
\hline Co 228.615 & 1.2 & 0.9982 & 0.0026 & 0.036 & $103.0 \%$ & 8.0 & 1.6 & 0.36 & $104.6 \%$ & 4.4 & 0.8 & \begin{tabular}{|l|} 
\\
\end{tabular} & $92.6 \%$ & 1.2 & 1.1 & 1.8 & $95.3 \%$ & 0.9 & 1.2 & 5.0 & $101.9 \%$ & 2.0 & 1.7 \\
\hline Co 238.892 & 2.0 & \begin{tabular}{|l|l|} 
\\
\end{tabular} & \begin{tabular}{|l|l|}
0.0025 \\
\end{tabular} & \begin{tabular}{|l|}
0.036 \\
\end{tabular} & $104.0 \%$ & 8.8 & 1.9 & \begin{tabular}{|l|}
0.36 \\
\end{tabular} & $103.2 \%$ & 4.2 & 0.7 & \begin{tabular}{|l|}
0.72 \\
\end{tabular} & $91.1 \%$ & 1.8 & 2.1 & 1.8 & $93.7 \%$ & 1.3 & 1.2 & 5.0 & $98.9 \%$ & 1.9 & 1.3 \\
\hline Cr 267.716 & 1.4 & \begin{tabular}{|l|l|} 
\\
\end{tabular} & \begin{tabular}{|l|l|}
0.0049 \\
\end{tabular} & \begin{tabular}{|l|}
0.036 \\
\end{tabular} & $99.4 \%$ & 1.7 & 1.0 & \begin{tabular}{|l|} 
\\
\end{tabular} & $106.1 \%$ & 4.3 & 0.7 & \begin{tabular}{|l|}
0.72 \\
\end{tabular} & $94.2 \%$ & 1.2 & 1.3 & 1.8 & $96.6 \%$ & 1.1 & 1.4 & 5.0 & $104.4 \%$ & 1.7 & 1.7 \\
\hline Cu 324.754 & 1.9 & 0.9973 & \begin{tabular}{|l|l|}
0.0069 \\
\end{tabular} & \begin{tabular}{|l|}
0.036 \\
\end{tabular} & $105.2 \%$ & 10.0 & 1.4 & \begin{tabular}{|l|}
0.36 \\
\end{tabular} & $107.4 \%$ & 4.1 & 0.8 & \begin{tabular}{|l|}
0.72 \\
\end{tabular} & $94.1 \%$ & 1.0 & 1.2 & 1.8 & $97.0 \%$ & 1.2 & 1.1 & 5.0 & $105.7 \%$ & 1.9 & 1.7 \\
\hline Cu 327,395 & 2.3 & \begin{tabular}{|l|}
0.9974 \\
\end{tabular} & \begin{tabular}{|l|l|} 
\\
\end{tabular} & \begin{tabular}{|l|}
0.036 \\
\end{tabular} & $104.3 \%$ & 8.5 & 1.6 & \begin{tabular}{|l|}
0.36 \\
\end{tabular} & $107.5 \%$ & 4.3 & 0.9 & \begin{tabular}{|l|}
0.72 \\
\end{tabular} & $94.3 \%$ & 1.0 & 1.3 & 1.8 & $97.6 \%$ & 0.9 & 1.4 & 5.0 & $106.1 \%$ & 1.8 & 1.7 \\
\hline $\mathrm{Fe} 238.204$ & 24.0 & \begin{tabular}{|l}
0.9954 \\
\end{tabular} & \begin{tabular}{|l|l|}
0.1715 \\
\end{tabular} & \begin{tabular}{|l|}
0.800 \\
\end{tabular} & $103.1 \%$ & 7.2 & 0.9 & \begin{tabular}{|l|l|}
8.00 \\
\end{tabular} & $115.6 \%$ & 2.7 & 1.4 & \begin{tabular}{|l|}
16.00 \\
\end{tabular} & $101.2 \%$ & 0.2 & 0.8 & 40.0 & $101.9 \%$ & 0.5 & 1.9 & \begin{tabular}{|l|}
100.0 \\
\end{tabular} & $86.7 \%$ & -18.4 & 2.9 \\
\hline $\mathrm{Fe} 259.940$ & 16.1 & 0.9954 & \begin{tabular}{|l|} 
\\
\end{tabular} & 0.800 & $103.5 \%$ & 7.5 & 1.1 & 8.00 & $116.0 \%$ & 2.7 & 1.4 & 16.00 & $102.0 \%$ & 1.2 & 2.1 & 40.0 & $101.8 \%$ & 0.4 & 1.9 & 100.0 & $86.7 \%$ & -16.7 & 2.7 \\
\hline K 766.491 & 37.7 & 0.9922 & ND & 1.080 & $107.8 \%$ & 8.4 & 2.0 & 10.80 & $94.3 \%$ & 2.7 & 2.0 & 21.60 & $86.8 \%$ & 3.2 & 0.9 & 54.0 & $92.1 \%$ & 1.0 & 1.8 & 100.0 & $110.1 \%$ & 2.9 & 0.8 \\
\hline К 769.897 & 32.7 & 0.9853 & ND & 1.080 & $104.9 \%$ & 4.5 & 2.3 & 10.80 & $86.3 \%$ & 2.3 & 1.6 & 21.60 & $81.6 \%$ & 3.2 & 1.1 & 54.0 & $92.3 \%$ & 1.2 & 1.9 & 100.0 & $119.5 \%$ & 3.1 & 0.8 \\
\hline Mg 279.078 & 16.1 & 0.9984 & \begin{tabular}{|l|} 
\\
\end{tabular} & 0.800 & $103.9 \%$ & 7.9 & 0.7 & 8.00 & $110.2 \%$ & 4.3 & 0.5 & 16.00 & $98.1 \%$ & 1.4 & 1.3 & 40.0 & $102.8 \%$ & 1.0 & 1.4 & 100.0 & $93.3 \%$ & 0.0 & 21.8 \\
\hline Mg 279.553 & 21.3 & 0.9767 & \begin{tabular}{|l|l|}
0.6765 \\
\end{tabular} & \begin{tabular}{|l|}
0.800 \\
\end{tabular} & $105.6 \%$ & 12.4 & 1.1 & 8.00 & $156.1 \%$ & 1.9 & 1.7 & \begin{tabular}{|l|}
16.00 \\
\end{tabular} & $127.5 \%$ & 0.9 & 1.4 & 40.0 & $100.3 \%$ & 0.5 & 1.6 & \begin{tabular}{|l|}
100.0 \\
\end{tabular} & $55.2 \%$ & 0.0 & 9.7 \\
\hline Mg 280.270 & 22.2 & \begin{tabular}{|l|l|} 
\\
\end{tabular} & \begin{tabular}{|l|l|}
0.3522 \\
\end{tabular} & \begin{tabular}{|l|}
0.800 \\
\end{tabular} & $104.0 \%$ & 9.3 & 1.4 & \begin{tabular}{|l|l|} 
\\
\end{tabular} & $132.0 \%$ & 3.1 & 1.7 & 16.00 & $114.1 \%$ & 0.5 & 0.9 & 40.0 & $101.7 \%$ & 2.0 & 1.2 & \begin{tabular}{|l|}
100.0 \\
\end{tabular} & $68.8 \%$ & 0.0 & 5.6 \\
\hline Mn 257.610 & 1.1 & 0.9987 & \begin{tabular}{|l|} 
\\
\end{tabular} & 0.036 & $103.6 \%$ & 7.7 & 1.0 & 0.36 & $108.7 \%$ & 2.5 & 1.3 & \begin{tabular}{|l|} 
\\
\end{tabular} & $95.2 \%$ & 1.7 & 2.1 & 1.8 & $95.8 \%$ & 0.4 & 1.7 & 5.0 & $101.5 \%$ & 2.1 & 1.0 \\
\hline Мo 202.032 & 135.7 & 0.9983 & ND & \begin{tabular}{|l|} 
\\
\end{tabular} & $103.3 \%$ & 4.1 & 0.8 & 0.36 & $109.1 \%$ & 3.6 & 1.8 & \begin{tabular}{|l|} 
\\
\end{tabular} & $95.9 \%$ & 1.1 & 1.2 & 1.8 & $99.4 \%$ & 0.7 & 1.2 & 5.0 & $106.2 \%$ & 1.6 & 1.7 \\
\hline Na 568.821 & 364.5 & 0.9925 & \begin{tabular}{|l|} 
\\
\end{tabular} & 0.800 & $113.3 \%$ & 11.5 & 12.3 & 8.00 & $113.8 \%$ & 4.1 & 1.7 & 16.00 & $97.9 \%$ & 3.8 & 1.3 & 40.0 & $101.3 \%$ & 0.3 & 1.4 & 100.0 & $75.6 \%$ & -22.1 & 39.1 \\
\hline Na 588.995 & 18.3 & 0.9670 & \begin{tabular}{|l|}
1.1995 \\
\end{tabular} & 0.800 & $113.5 \%$ & 18.3 & 1.3 & 8.00 & $134.1 \%$ & 4.0 & 2.2 & 16.00 & $112.3 \%$ & 2.4 & 0.8 & 40.0 & $99.9 \%$ & 1.6 & 1.0 & 100.0 & $64.1 \%$ & -29.2 & 1.1 \\
\hline Na 589.592 & 34.5 & 0.9780 & \begin{tabular}{|l|l|} 
\\
\end{tabular} & 0.800 & $111.1 \%$ & 16.8 & 2.1 & 8.00 & $120.2 \%$ & 4.0 & 2.2 & 16.00 & $105.8 \%$ & 2.6 & 0.9 & 40.0 & $101.1 \%$ & 1.6 & 1.2 & 100.0 & $67.8 \%$ & -45.6 & 1.6 \\
\hline Ni 230.299 & 1.4 & 0.9982 & 0.0031 & 0.036 & $101.4 \%$ & 4.8 & 1.1 & 0.36 & $105.5 \%$ & 4.2 & 0.8 & \begin{tabular}{|l|} 
\\
\end{tabular} & $93.2 \%$ & 1.5 & 1.2 & 1.8 & $94.8 \%$ & 0.7 & 1.0 & 5.0 & $100.9 \%$ & 1.7 & 1.5 \\
\hline Ni 231.604 & 1.2 & 0.9983 & \begin{tabular}{|l|} 
\\
\end{tabular} & 0.036 & $101.5 \%$ & 4.0 & 0.8 & 0.36 & $104.8 \%$ & 3.2 & 1.8 & \begin{tabular}{|l|}
0.72 \\
\end{tabular} & $92.1 \%$ & 1.4 & 1.2 & 1.8 & $94.7 \%$ & 1.1 & 1.0 & 5.0 & $100.7 \%$ & 1.7 & 1.6 \\
\hline P 213.618 & 1.9 & 0.9960 & \begin{tabular}{|l|} 
\\
\end{tabular} & 0.080 & $102.2 \%$ & 6.5 & 0.6 & 0.80 & $106.1 \%$ & 4.5 & 0.6 & 1.60 & $95.9 \%$ & 1.1 & 1.5 & 4.0 & $102.5 \%$ & 1.1 & 1.1 & - & - & - & - \\
\hline P 214.914 & 4.5 & 0.9955 & \begin{tabular}{|l|} 
\\
\end{tabular} & \begin{tabular}{|l|l|} 
\\
\end{tabular} & $102.6 \%$ & 6.6 & 2.2 & 0.80 & $108.4 \%$ & 3.2 & 1.8 & 1.60 & $96.7 \%$ & 2.8 & 1.1 & 4.0 & $102.7 \%$ & 1.3 & 1.4 & - & - & - & - \\
\hline $\mathrm{Pb} 220.353$ & 1.6 & 0.9984 & \begin{tabular}{|l|}
0.0027 \\
\end{tabular} & 0.036 & $105.7 \%$ & 8.0 & 3.5 & 0.36 & $96.3 \%$ & 3.3 & 2.0 & \begin{tabular}{|l|} 
\\
\end{tabular} & $85.2 \%$ & 2.3 & 1.1 & 1.8 & $94.2 \%$ & 0.7 & 1.3 & 5.0 & $99.9 \%$ & 1.6 & 1.6 \\
\hline S 181.972 & 5.5 & 0.9964 & 0.0491 & 0.080 & $106.7 \%$ & 17.8 & 0.9 & 0.80 & $104.8 \%$ & 2.9 & 1.8 & 1.60 & $95.0 \%$ & 3.2 & 1.2 & 4.0 & $101.2 \%$ & 1.1 & 1.4 & - & - & - & - \\
\hline S 182.562 & 5.9 & 0.9964 & \begin{tabular}{|l|} 
\\
\end{tabular} & 0.080 & $108.2 \%$ & 16.9 & 7.8 & 0.80 & $104.6 \%$ & 3.2 & 2.3 & 1.60 & $94.9 \%$ & 2.9 & 1.1 & 4.0 & $102.2 \%$ & 1.2 & 1.3 & - & - & - & - \\
\hline Sb 206.834 & 6.2 & 0.9988 & 0.0030 & 0.008 & $96.5 \%$ & 15.7 & 13.6 & 0.08 & $105.9 \%$ & 4.2 & 3.4 & \begin{tabular}{|l|} 
\\
\end{tabular} & $95.1 \%$ & 2.4 & 2.6 & 0.4 & $102.3 \%$ & 1.4 & 1.8 & 1.0 & $95.2 \%$ & 4.0 & 2.7 \\
\hline Se 196.026 & 30.1 & \begin{tabular}{|l|l|} 
\\
\end{tabular} & \begin{tabular}{|l|l|}
0.0380 \\
\end{tabular} & \begin{tabular}{|l|}
0.036 \\
\end{tabular} & $93.1 \%$ & 22.2 & 4.6 & \begin{tabular}{|l|}
0.36 \\
\end{tabular} & $111.3 \%$ & 3.6 & 2.3 & \begin{tabular}{|l|}
0.72 \\
\end{tabular} & $98.3 \%$ & 3.2 & 1.2 & 1.8 & $105.6 \%$ & 2.1 & 1.8 & 5.0 & $116.0 \%$ & 1.3 & 1.4 \\
\hline Si 251.611 & 27.0 & \begin{tabular}{|l|l|} 
\\
\end{tabular} & \begin{tabular}{|l|l|} 
\\
\end{tabular} & \begin{tabular}{|l|}
0.080 \\
\end{tabular} & $106.1 \%$ & 10.2 & 1.1 & \begin{tabular}{|l|}
0.80 \\
\end{tabular} & $111.8 \%$ & 1.5 & 1.4 & \begin{tabular}{|l|}
1.60 \\
\end{tabular} & $96.4 \%$ & 1.4 & 1.1 & 4.0 & $102.2 \%$ & 2.1 & 0.9 & - & - & - & - \\
\hline Sn 189.927 & 2.3 & \begin{tabular}{|l|l|} 
\\
\end{tabular} & \begin{tabular}{|l|l|}
0.0080 \\
\end{tabular} & \begin{tabular}{|l|}
0.004 \\
\end{tabular} & $119.5 \%$ & 26.6 & 10.6 & \begin{tabular}{|l|}
0.04 \\
\end{tabular} & $121.4 \%$ & 4.7 & 3.6 & \begin{tabular}{|l|}
0.08 \\
\end{tabular} & $110.7 \%$ & 2.6 & 1.4 & 0.2 & $98.8 \%$ & 2.5 & 2.0 & - & - & - & - \\
\hline Sr 407.771 & 23.2 & 0.8868 & \begin{tabular}{|l|} 
\\
\end{tabular} & \begin{tabular}{|l|} 
\\
\end{tabular} & $104.2 \%$ & 10.4 & 1.0 & 8.28 & $115.2 \%$ & 2.9 & 1.4 & 16.56 & $91.1 \%$ & 1.4 & 1.3 & 41.4 & $69.4 \%$ & 1.0 & 0.8 & 105.0 & $38.7 \%$ & 1.6 & 0.9 \\
\hline Th 288.505 & 3.6 & 0.9982 & \begin{tabular}{|l|}
0.0072 \\
\end{tabular} & 0.008 & $94.8 \%$ & 7.9 & 15.7 & 0.08 & $104.3 \%$ & 2.4 & 3.1 & \begin{tabular}{|l|} 
\\
\end{tabular} & $94.7 \%$ & 2.2 & 1.5 & 0.4 & $100.9 \%$ & 0.5 & 2.1 & 1.0 & $90.9 \%$ & 1.3 & 2.9 \\
\hline T1 190.794 & 5.8 & 0.9978 & ND & 0.008 & $70.9 \%$ & 7.7 & 36.7 & 0.08 & $0.0 \%$ & 4.7 & 2.2 & \begin{tabular}{|l|} 
\\
\end{tabular} & $0.0 \%$ & 2.0 & 1.8 & 0.4 & $103.1 \%$ & 2.1 & 0.9 & 1.0 & $93.5 \%$ & 1.0 & 6.9 \\
\hline V 292.401 & 0.9 & 0.9970 & \begin{tabular}{|l|} 
\\
\end{tabular} & 0.008 & $101.8 \%$ & 8.6 & 3.5 & 0.08 & $111.6 \%$ & 3.5 & 1.8 & \begin{tabular}{|l|} 
\\
\end{tabular} & $98.8 \%$ & 1.0 & 1.3 & 0.4 & $102.3 \%$ & 1.0 & 1.1 & 1.0 & $89.4 \%$ & - & 48.3 \\
\hline Y 360.074 & 2.1 & 0.9992 & ND & 0.080 & $103.9 \%$ & 8.8 & 0.9 & 0.80 & $111.9 \%$ & 2.8 & 1.4 & 1.60 & $98.2 \%$ & 1.5 & 2.1 & 4.0 & $101.8 \%$ & 0.7 & 2.1 & - & - & - & - \\
\hline Y 371.029 & 2.2 & 0.9987 & ND & 0.080 & $104.2 \%$ & 8.9 & 1.2 & 0.80 & $113.1 \%$ & 2.9 & 1.4 & 1.60 & $99.4 \%$ & 1.4 & 2.1 & 4.0 & $102.4 \%$ & 1.4 & 1.3 & - & - & - & - \\
\hline $\mathrm{Zn} 202.548$ & 0.7 & 0.9978 & \begin{tabular}{|l|} 
\\
\end{tabular} & 0.036 & $108.8 \%$ & 12.4 & 0.8 & 0.36 & $103.0 \%$ & 5.1 & 0.9 & 0.72 & $94.9 \%$ & 4.0 & 1.5 & 1.8 & $96.0 \%$ & 0.7 & 1.2 & 5.0 & $103.3 \%$ & 1.8 & 1.5 \\
\hline Zn 206.200 & 1.3 & 0.9979 & $0.0085 \mid$ & 0.036 & $108.3 \%$ & 11.5 & 1.8 & 0.36 & $102.9 \%$ & 3.7 & 2.1 & \begin{tabular}{|l|}
0.72 \\
\end{tabular} & $94.5 \%$ & 3.0 & 1.1 & 1.8 & $95.9 \%$ & 1.0 & 1.1 & 5.0 & $103.1 \%$ & 1.6 & 1.7 \\
\hline $\mathrm{Zn} 213.857$ & 0.9 & 0.9951 & \begin{tabular}{|l|l|}
0.0069 \\
\end{tabular} & \begin{tabular}{|l|}
0.036 \\
\end{tabular} & $108.3 \%$ & 12.2 & 0.7 & \begin{tabular}{|l|}
0.36 \\
\end{tabular} & $99.4 \%$ & 4.0 & 0.6 & \begin{tabular}{|l|l|}
0.72 \\
\end{tabular} & $91.3 \%$ & 3.5 & 1.3 & 1.8 & $93.6 \%$ & 1.1 & 1.5 & 5.0 & $103.8 \%$ & 1.9 & 1.6 \\
\hline
\end{tabular}




\section{REFERENCES}

[1] Ma F.; Hanna, M.A. Biodiesel production: a review. Bioresource Technol., 1999, 70, 1-15.

[2] Fukuda, H.; Kond, A; Noda, H. Biodiesel fuel production by transesterification of oils. J. Biosci. Bioeng., 2001, 92(5), 405-416.

[3] Gerpen, J.V.; Shanks, B.; Pruszko, R.; Clements, D.; Knothe, G. Biodiesel production technology. Technical report, National Renewable Energy Laboratory. NREL/SR-510-36244, 2004.

[4] Holden, B.; Jack, J.; Miller, M.; Durbin, T. Effect of biodiesel on diesel engine nitrogen oxide and other regulated emissions. Technical Report \# WP-0308. Naval Facilities Engineering Command. Port Hueneme, California. USA, 2006.

[5] Knothe, G. Analyzing biodiesel: standards and other methods. $J$. Am. Oil. Chem. Soc., 2006, 83(10), 823-833.

[6] Woods, G.D.; Fryer, F.I. Direct elemental analysis of biodiesel by inductively coupled plasma-mass spectrometry. Anal. Bioanal. Chem., 2007, 389, 753-761.

[7] ASTM International. Standard Specification for Biodiesel Fuel Blend Stock (B100) for Middle Distillate Fuels. Annual Book of ASTM Standards, 2007, Vol. 05.03, ASTMD6751.

[8] European Committee for Standardization. Automotive fuels - Fatty acid methyl esters (FAME) for diesel engines - Requirements and test methods. EN 14214, 2003.

[9] ASTM International. Standard Test Method for Determination of Additive Elements in Lubricating Oils by Inductively Coupled Plasma Atomic Emission Spectrometry. Annual Book of ASTM Standards, 2007, Vol. 05.03, ASTM D4951-02.

[10] European Committee for Standardization. Fat and oil derivatives Fatty acid methyl ester (FAME) -Determination of $\mathrm{Ca}, \mathrm{K}, \mathrm{Mg}$ and $\mathrm{Na}$ content by optical emission spectral analysis with inductively coupled plasma (ICP-OES). EN 14538, 2006.

[11] Edlund, M.; Visser, H.; Heitland, P. Analysis of biodiesel by argon-oxygen mixed-gas inductively coupled plasma optical emission spectrometry. J. Anal. At. Spectrom., 2002, 17, 232-235.
[12] Onyeso, S. Analysis of gasoline and diesel fuel samples by inductively coupled plasma atomic emission spectrometry (ICPAES), using pneumatic nebulizer and standard spray chamber. $J$. ASTM Int. (JAI), 2005a, 2, 10

[13] Onyeso, S. Abstracts of 57th Southeast/61st Southwest Joint Regional Meeting of the American Chemical Society, Memphis, Nov. 1-4, 2005b.

[14] EPA Method Series. EPA test method 3051: Microwave assisted acid digestion of sediments, sludges, soils, and oils. Revision 0 . EPA Method 3051, 1994.

[15] EPA Method Series. Inductively coupled plasma - atomic emission spectrometric method for trace element analysis of water and wastes Revision 5. EPA Method 200.7, 1998.

[16] Bridger, S.; Knowles, M. A complete method for environmental samples by simultaneous axially viewed ICP-AES following USEPA guidelines. Technical paper Varian Inc. Victoria, Australia. 2000. (www.varianinc.com)

[17] Krammer, P.; Vogel, H. Hydrolysis of esters in subcritical and supercritical water. J. Supercrit. Fluid., 2000, 16, 189-206.

[18] McCormick, R.L.; Alleman, T.L.; Ratcliff, M.; Moens, L.; Lawrence, R. Survey of the quality and stability of biodiesel and biodiesel blends in the United States in 2004. Technical report. National Renewable Energy Laboratory, NREL/TO-540-38836, 2005

[19] Mazzocchia, C.; Modica, G.; Kaddouri, A.; Nannicini, R. Fatty acid methyl esters synthesis from triglycerides over heterogeneous catalysts in the presence of microwaves. Comp. Rend. Chim., 2004 7, 601-605.

[20] Kusdiana, D.; Saka, S. Methyl esterification of free fatty acids of rapeseed oil as treated in supercritical methanol. J. Chem. Eng. Jpn., 2001, 34, 383-387.

[21] Khuwijitjaru, P.; Adachi, S.; Matsuno, R. Solubility of saturated fatty acids in water at elevated temperatures. Biosci. Biotechnol. Biochem., 2002, 66(8), 1723-1726.

(C) Iqbal et al.; Licensee Bentham Open.

This is an open access article licensed under the terms of the Creative Commons Attribution Non-Commercial License (http://creativecommons.org/licenses/by-nc/ $3.0 /$ ) which permits unrestricted, non-commercial use, distribution and reproduction in any medium, provided the work is properly cited. 